\title{
Chronological development in coal pillar design for bord and pillar workings: A critical appraisal
}

\author{
M. Jawed ${ }^{1 \star}$, R. K. Sinha ${ }^{2}$ and S. Sengupta ${ }^{3}$ \\ ${ }^{1}$ Department of Mining Engineering and Chairman, JEE-ISM, Indian School of Mines, Dhanbad-826004, \\ Jharkhand, India. \\ ${ }^{2}$ Indian School of Mines, Dhanbad, India. \\ ${ }^{3}$ National Institute of Rock Mechanics, India.
}

Accepted 16 January, 2013

\begin{abstract}
In this study, proper design of coal pillar has ever remained a difficult and challenging task because of two conflicting objectives, namely the conservation of coal on one hand that requires coal pillars to be of minimum size and stability of pillars, and on the other hand that ensures safety of working. The complex loading conditions, the occurrence of seams in close succession and geological abnormalities present in seams make the design problems of coal even more complex and complicated. An attempt has been made in this paper to enlist and describe briefly factors affecting pillar strength and empirical strength equations/formulae developed by different researchers in different parts around the globe. Further, a comparative study has been made for a given set of geo-mining conditions to know the suitability of these equations in terms of their being either over-estimators or under-estimators.
\end{abstract}

Key words: Pillar strength, coal pillar design, pillar strength.

\section{INTRODUCTION}

Bord and pillar method of mining coal seam involves driving two sets of parallel inseam headings, one set being orthogonal to another, thereby forming square or rectangular pillars. These pillars are subsequently extracted allowing the overlying strata to cave in the decoaled area. In some cases where circumstances so demand, decoaled area is packed with incombustible material to avoid caving of the roof in order to keep the surface intact and free from any subsidence.

The design of coal pillars remains one of the most difficult tasks because of two conflicting requirements to be fulfilled. On one hand, the size of the pillar should be as small as possible to enable maximum recovery of coal, while on the other hand, the pillar should be large enough to support the load of overlying strata. The design problem complicates further due to the interaction of multiple factors such as complex loading conditions, natural variation within the coal seam, influence of contiguous seam workings, geological abnormalities etc.

*Corresponding author. E-mail: profmjawed@yahoo.com. Tel:/Fax: +91326 2296628.
Like design of any other structure, the design procedure of coal pillars in bord and pillar mines essentially consists of knowing precisely the strength of coal pillar, the load on the pillar (cover weight) and linking the two with a desirable factor of safety. Researchers in different countries have developed empirical relations for estimation of strength of coal pillars for the geo-mining conditions of the coal mines in their own countries. Thus, the empirical relation developed for a particular set of conditions will not be precisely applicable to another set of conditions existing in other country. This paper, therefore, seeks to present a critical review of pillar design by different researchers around the globe.

\section{FACTORS AFFECTING THE PILLAR STRENGTH}

Pillar strength is a function of a host of factors, the most significant being depth of seam from the surface, height of working, thickness of seam, dip of the seam, width of galleries, strength of coal, strength of roof and floor rocks, geological abnormalities in the seam (fold, fault, presence of band etc.), presence of water and weathering underground, proposed layout such as partial extraction 


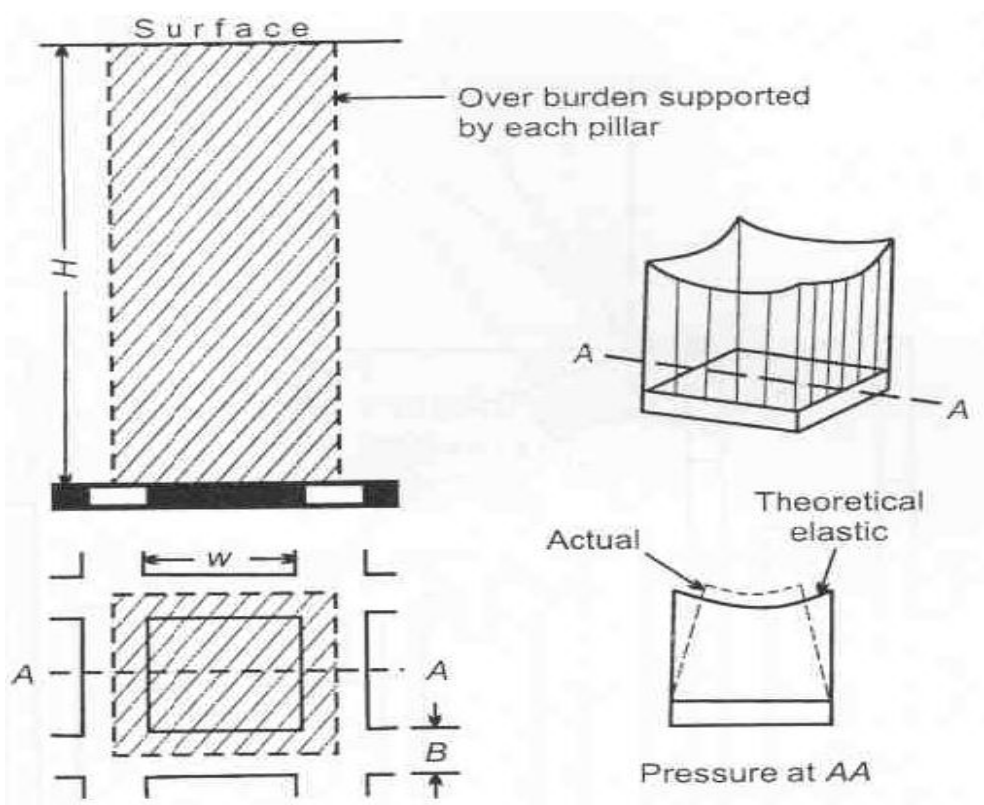

Figure 1. Pillar load according to tributary area theory in a wide array.

or full extraction, uniaxial and triaxial strength of coal, width-to-height ratio of pillar, shape of pillar (square or rectangular), pre-excavation horizontal stresses, condition of roof-pillar and floor-pillar contacts, method of gallery drivage (blasting or road header/continuous miner) etc.

\section{PILLAR LOAD}

The load on pillars comprises of the vertical virgin stress (in level or near level coal seams) and the stress induced by the excavations around pillars. For inclined seams, the virgin horizontal stress must also be considered.

\section{Pillar arrays in level seams}

On a regular array consisting pillars of a more or less uniform shape and size, the vertical virgin stress is taken equal to the cover weight of the strata in normal coal measures. However, in geologically disturbed areas, in situ stress measurement results should be used. Figure 1 shows the block of overlying rocks each pillar has to support. The average rock pressure "P" over the pillar is simply the weight of this block divided by the pillar area.

For square pillar

$$
P=\gamma H\left(\frac{W+B}{W}\right)^{2}
$$

For rectangular pillar
$P=\gamma H \frac{(W+B)(L+B)}{W L}$

Where, $\mathrm{H}$ is the depth of the seam, $\mathrm{W}$ is the width of pillar, $L$ is the length of pillar and $B$ is the bord width. These equations work very well in practice for regular arrays provided the width of the panel is at least equal to the depth of cover. If it is less, the pillar load may be less. The most commonly accepted pressure distribution over a pillar in an infinitely wide uniform pillar array is shown in Figure 1 the average being given by Equations 1 and 2 for square and rectangular pillar, respectively.

In an irregular pillar arrays or for panels whose width is less than the depth of cover $(\mathrm{H})$, the load is overestimated for small pillars by tributary area theory and underestimated for large pillars. Under hard sandstones, the over and underestimation in irregular arrays will be further magnified and over a narrow pillar panel, the pillar load will be further reduced. In such situation, it is best to adopt numerical methods, the displacement discontinuity method being probably the most convenient (Sheorey, 2006).

\section{Pillar arrays in inclined seams}

The rock pressure normal to inclined seam pillar arrays is given by Trumbachev and Melnikov (1964) as:

$P=\gamma H\left(\frac{W+B}{W}\right)^{2} \cdot\left(\operatorname{Cos}^{2} \alpha+K \operatorname{Sin}^{2} \alpha\right)$

Where $\alpha$ is the angle of inclination of the seam with the 
horizontal, and $\mathrm{K}$ is the ratio of horizontal to vertical stresses.

\section{Coal pillar strength equations developed by different researchers under different conditions}

The journey of pillar design method started with the consideration of scale effects of the laboratory size specimens to extrapolate for the actual size of mine pillars. This included the testing of rock at laboratory scale. Subsequently, the design got modified with large scale in situ tests. Wagner (1974) brought a paradigm shift in the design of pillars by introducing the core confinement concept. This was later on advanced by Das (1986) using the concept of squat pillars (pillars having a width to height ratio greater than 4 to 6 ).

\section{Pillar strength concept by Bunting}

The science of pillar design can be traced back to Coulomb in 1773 (Mark, 2006). However, the first scientific approach to pillar design for coal mines can be attributed to Bunting (1911). Bunting carried out exhaustive tests on various sizes of cubes (2 to 6 inches size) and prisms (2.25 to 12.25 inches high) of anthracite. The results of tests were tabulated with reference to the size of specimens and the ratio of height to lateral dimension. They demonstrated that the coal prisms followed some law of strength relative to their height and breadth. Based on this laboratory experiments, they conducted back-analysis of full-scale pillar failures underground.

Using the same approach as followed by Bunting, a number of pillar design equations were developed around the globe for the next seven-decades. During this period, many researchers had recognized that the pillar strength is influenced significantly by the width to height ratio. This research on size effect dragged for a sufficiently longer duration.

\section{Pillar strength equation by Zern Edward Nathan}

Zern (1928) edition of his book titled "Coal Miner's Pocketbook" gave the following equation for the strength of coal pillars:

$C_{p}=C_{1} \sqrt{\left(\frac{\left(r_{p}\right.}{h_{p}}\right)}$

Where, $C_{p}$ is the pillar strength, $C_{1}$ is the coal strength parameter $=4.8$ to $7.0 \mathrm{MPa}$ (700 to $1000 \mathrm{psi}$ ) $W_{p}$ is the pillar width and $h_{p}$ is the pillar height.

\section{Pillar strength equation by Greenwald}

Greenwald et al. (1941) considered in situ tests on slender pillars of size $30 \mathrm{~cm}$ and gave the strength of pillar as:

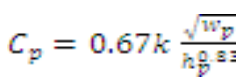

Where, $C_{p}$ is the pillar strength, $k$ is the strength of unit cube of coal sample, $w_{p}$ is the pillar width and $h_{p}$ is the pillar height. This equation was developed on a limited number of 7 samples with low correlation coefficient, thus inefficient.

\section{Pillar strength equation by Holland and Gaddy}

Gaddy (1956) used coal samples of various cube sizes from five different seams. He tried to establish relation between laboratory specimen strength and strength of actual pillar. Gaddy was of the opinion that the strength decreases with increasing size of specimens which he expressed as follows:

$k_{i g}=s_{\mathbb{Q}} / \sqrt{d_{19}}$

Where, $k_{G}$ is the Gaddy constant [estimated strength of a $2.5 \mathrm{~cm}$ (1 inch) cube], $S_{c}$ is the strength of coal specimen and $d_{G}$ is the dimension of the specimen in inch.

His work (Holland and Gaddy, 1964) became popular as 'Holland-Gaddy Pillar Strength Equation' as given as follows:

$C_{p}=\mathbb{K}_{i g} \frac{\sqrt[4]{\sqrt{15 T_{p}}}}{\sqrt{\mathbb{R}_{p}}}$

Where, $C_{p}$ is the pillar strength, $w_{p}$ is the pillar width and $h_{p}$ is the pillar height. The strength equation is applicable to slender pillars.

\section{Coal mines regulation versus pillar size}

In India, the dimensions of the pillars are regulated by Regulation 99(4) of Coal Mines Regulation 1957 (CMR, 1957). The regulation stipulates that the width of galleries shall not exceed $4.8 \mathrm{~m}$ and height of galleries shall not exceed $3 \mathrm{~m}$. For different width of galleries varying from 3 to $4.8 \mathrm{~m}$ and for different depth of working, the Regulation stipulates the minimum dimension of pillars.

\section{Pillar strength equation by Salamon and Munro}

Salamon and Munro (1967) carried out an intensive investigation into the strength of coal pillars by analyzing 
statistically 96 intact and 27 collapsed pillar geometries from South African coal mines. The following empirical relation developed for strength of pillar became quite popular.

$C_{\mathrm{p}}=k_{\mathrm{EN}} h_{\mathrm{p}}^{\mathrm{Q}} w_{\mathrm{p}}^{\beta}$

Where, $C_{p}$ is the pillar strength, $k_{S M}=7.176 \mathrm{kPa}, h_{p}$ is the pillar height, $w_{p}$ is the pillar width, $\alpha=-0.66$ and $\beta=0.46$.

The main reason for the popularity of Salamon and Munro (1967) equation was that the data was used from the mines and the strength was taken as the mean strength of coal pillars as opposed to the strength of coal specimens. The strength equation is applicable to slender pillars. For evaluation of long-term stability of Indian coal pillars, Sheorey et al. (1986) generalized the Salamon and Munro (1967) equation as $C_{p}=0.79 \mathrm{k} w_{p}^{0.46} / h_{p}^{0.66}$

where $k$ has to be evaluated by testing of specimens of size $30 \mathrm{~cm}$.

\section{Pillar strength equation by Obert and Duvall}

Obert and Duvall (1967) developed empirical relation for the compressive strength of specimens having height-todiameter (or width) ratio as 0.25 to 4.0 .

$C_{80}=C_{10}\left[0.778+0.222\left(\frac{d}{2}\right)\right]$

Where, $C_{10}$ is the compressive strength of specimens having ratio of $\frac{d}{h}=1, C_{10}$ is the compressive strength of a specimen having $d / h=1, d$ is the diameter of the specimen and $h$ is the height of the specimen.

They suggested that the compressive strength of a rib pillar in a massive elastic rock can be approximated by the use of Equation 9, provided $d$ and $h$ are replaced, respectively by $w_{p}$ and $h_{p}$.

$C_{\mathrm{p}}=C_{10}\left[0.778+0.222\left(\frac{10}{h_{p}}\right)\right]$

Where, $C_{p}$ is the compressive strength of the pillar, $w_{p}$ is the width of pillar and $h_{p}$ is the height of the pillar. The strength equation is applicable for slender pillars. They argued that the results based on above calculations would yield strength on a conservative side for the following reasons:

i) The compressive strength of a specimen having cross sectional dimensions $W$ and $L$ normal to the applied load, with $W<L$, is stronger than a specimen with circular cross section of diameter $\mathrm{W}$,

ii) If the surfaces of pillar are concave, when formed by driving circular openings, the strength of such pillar would be greater than that of a pillar with straight sides which is due to driving of rectangular openings.

iii) The end constraint on a pillar formed in a rock continuum would be greater than the end constraint normally employed in a standard compressive test, a factor that would increase the pillar strength to some extent.

\section{Pillar strength equation by Cook}

Cook et al. (1971) advocated for the use of yielding pillars between the barrier pillars for an improved extraction ratio of coal. For the design of yield pillars, the knowledge of complete stress strain curve of the pillar was a prerequisite. They utilized a stiff $100 \mathrm{MN}$ jacking system for measuring the complete load-displacement curves of pillars with cross sections up to $2 \times 2 \mathrm{~m}$. The equation is given as follows:

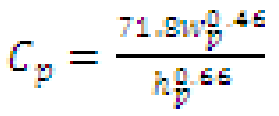

Where, $C_{p}$ is the strength of the pillar, $w_{p}$ and $h_{p}$ are the width and height of the pillars, respectively.

They concluded that a residual strength of only 1 bar for a crushed pillar is sufficient to provide roof support of $0.1 \mathrm{MN} / \mathrm{m}^{2}$ of pillar cross section. They also observed that the average strength of the pillars was conforming to the Salamon and Munro (1967) relation. The stress versus compression curve at the center of the pillar had the highest peak indicating that the core of the pillar was quite strong.

\section{Wagner approach to pillar design}

Wagner (1974) also realized that, the center portion of a pillar was capable to withstand high stresses even when the pillar has been compressed beyond its maximum resistance or the strength of the pillar. Wagner (1974) observed that the failure commences at the circumference of the pillar and migrates towards the center of the pillar. At the time of overall structural failure of the pillar, the central position of the pillar had not reached its full load bearing potential. The strength of circumferential portion of a pillar was independent of the sample width to height ratio, whereas the strength of its center increases with increasing width to height ratio.

Wagner (1980) suggested that the Salamon and Munro (1967) equation was the result of a large number of case histories of failed and stable cases of South African bord and pillar mining which have been formed by drilling and blasting. Wagner (1980) considered the blasting damage on the skin of the coal pillar that reduced the pillar width up to $0.3 \mathrm{~m}$. If the pillars are formed by cutting, say with continuous miners, the pillar strength will be more as the 
skin damage does not occur. He quantified the benefits gained in terms of pillar strength and safety factor on account of using continuous miners as:

$$
S=C_{p}\left(1+\Delta w / w_{0}\right)^{246}
$$

Where $w_{o}$ is the nominal pillar width and $\Delta w$ is the effective increase in pillar width as a result of preserving the skin of the pillar.

\section{Wilson's approach to pillar design}

Wilson (1972b) carried out a mechanistic model of the pillar with a theoretical basis that could be applied to both slender and squat pillars. Later on, Wilson (1983) advanced his pillar equation for different conditions. Wilson's approach had a number of simplifying assumptions, important one being the assumption that the linear variation of the coal triaxial strength, however, practically it is observed to be nonlinear. The guiding principle for the development of Wilson's (1983) equation was that it could estimate vertical stress gradient within the yield zone, which was then integrated over the area of the pillar to arrive at the ultimate pillar resistance. The Wilson's equation with different cases in chronological order is enumerated below. All equations are in ton, feet units.

\section{Wilson's (1972b) Equation}

Case I: $\left[w_{p}>2 \bar{x}\right]$

For rectangular pillars

$C_{p}=\frac{4 \% H}{w_{1} W_{2}}\left[w w_{1}-1.5\left(w+w_{1}\right) h_{p} H \times 10^{-9}+3 h_{p}^{2} H^{2} \times 10^{-6}\right]$

For long pillars

$C_{p}=\frac{4 V H}{W}\left(w-1.5 h_{p} H \times 10^{-g}\right.$

Case II $\left[w_{p}<2 \bar{x}\right]$

For rectangular pillars

$C_{\mathrm{p}}=667 \mathrm{~V} \frac{\mathrm{W}}{\mathrm{aw} H}\left[w_{1}-\frac{w}{a}\right]$

For long pillars

$$
c_{p}=667 y \frac{w}{n}
$$

Where, $C_{\mathrm{p}}$ is the pillar strength, $\bar{x}=0.0015 h_{\mathrm{p}} H$ is the failed coal zone in the pillar, $\gamma=0.0707 \mathrm{t} / \mathrm{ft}^{\mathrm{a}}$ is the rock density, $H$ is the depth of the coal seam from surface, $w_{p}$ is the dimension of the square pillar and $w$ and $w_{1}$ are the plan dimensions of the pillar.

\section{Wilson's (1983) Equation}

\section{Case I: Stable roadways}

$C_{p}=\frac{1}{W W_{1}} \int_{G P}^{q W}(w-2 x)\left(w_{1}-2 x\right) d \sigma+q p+\frac{a_{p}}{W W_{1}}(w-2 x)\left(w_{1}-2 x\right)$

\section{Case II: Unstable roadways}

$C_{p}=\frac{1}{a v w_{1}} \int_{q p}^{\sigma \sigma}(w-2 x)\left(w_{1}-2 x\right) d \sigma+q p$, where

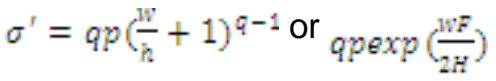

Where, $\sigma_{0}$ is the in-situ strength, $p=0.1 \mathrm{MPa}$ (a constant for broken coal), $q=3.0$ (triaxial constant). Both Equations 17 and 18 are subject to two ground conditions as described below:

Condition a: Yield in roof, seam and floor

$x=\frac{\pi}{2}\left[\left(\frac{\sigma}{q p}\right)^{1 /(q-1)}-1\right]^{\text {and }} \bar{x}=\frac{\pi}{2}\left[\left(\frac{h H}{p}\right)^{1 /(q-1)}-1\right]$

Condition b: Yield in seam, rigid roof and floor

$x=\frac{\pi}{f} \ln \frac{\sigma}{49} \quad$ and $\quad \bar{x}=\frac{\pi}{f} \ln \frac{W E}{p} \quad$ where, $F=\frac{q-1}{\sqrt{q}}+\frac{(q-1)^{2}}{q} \tan ^{-1} \sqrt{q}$

\section{Bieniawski approach to pillar design}

Bieniawski and Van (1975) based on his 8 years of in situ testing of 66 large coal specimens, up to $2 \mathrm{~m}$ in width and height and for width to height ratio ranging from 0.5 to 3.4 , he gave the following empirical relation for pillar strength:

$C_{p}=\mathbb{k}_{B}\left[0.64+0.34\left(\frac{\left(w_{p}\right.}{\hbar_{p}}\right)\right]$

Where, $C_{p}$ is the Pillar strength $(\mathrm{MPa}), k_{B}$ is the unconfined compressive strength of a $30 \mathrm{~cm}$ cube pillar specimen $(\mathrm{MPa}), w_{p}$ is the pillar width and $h_{p}$ is the pillar height. 
Bieniawski (1968) had proposed originally that empirical constants of 0.556 and 0.444 , instead of 0.64 and 0.34 , respectively could be used to describe pillar strength. Logie and Matheson (1982) modified the Bieniawski (1968) equation to suit for squat pillars by introducing a power of 1.4 as follows:

$C_{p}=k_{B}\left[0.64+0.34\left(\frac{w_{p}}{h_{p}}\right)\right]^{1.4}$

\section{Pillar strength equation by Hustrulid}

Hustrulid (1976) by this time had witnessed a number of equations all of which were unfolding the same phenomena. He came out with two predictive equations, namely the compressive strength-size relationship and the compressive strength- shape relationship which could be used to describe majority of experimental data very well.

Compressive strength-size relationship

$\sigma_{\text {ewbe }}=\frac{\mathbb{k}_{\text {if }}}{\sqrt{h_{\text {prism }}}}$ Whyriem $\leq 36$ inches

$\sigma_{\text {ewbe }}=\frac{k_{\text {hif }}}{\sqrt{26}} \forall h_{\text {prign }} \geq 36$ inches

Compressive strength-shape relationship

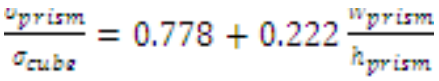

Where, $\sigma_{\text {cwbe }}$ is the compressive strength of cube (psi), $\sigma_{\text {prigm }}$ is the compressive strength of prism (psi), $\mathbb{k}_{\mathbb{H}}$ is the constant for each coal, $w_{\text {priam }}$ is the width of the sample (inch), $h_{\text {yyiam }}$ is height of the sample (inch).

\section{Pillar strength equation by Pariseau}

Pariseau (1982) presented the equation for the stresses acting on pillars in dipping seam that accounted for both the vertical and horizontal stress components. Equations 13 and 14 represent the normal and shear stresses respectively acting on inclined pillars. This is a variation of tributary area theory approach that takes into account both the components of in-situ stress viz. the vertical and horizontal components

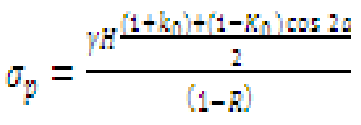

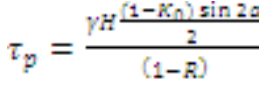

Where, $\sigma_{\mathrm{p}}$ is the average normal pillar stress (MPa), $\tau_{\mathrm{p}}$ is the average shear pillar stress (MPa), $\gamma$ is the unit weight of overburden $\left(\mathrm{MN} / \mathrm{m}^{3}\right), H$ is the depth below surface $(\mathrm{m})$, $K_{0}$ is the ratio of in-situ horizontal to vertical stress, $\mathbb{R}$ is the extraction ratio, $\alpha$ is the dip of seam (degrees). The limitation to this theory is that, Pariseau (1982) assumed the magnitudes of horizontal stresses to be equal in horizontal plane. This is not the case as has been observed in field investigations.

\section{Pillar equation by Agapito and Hardy}

Agapito and Hardy (1982) conducted finite element analysis of pillars and proposed the following equation:

$\frac{c_{p}}{K}=1+c\left(\frac{a_{k}}{K}\right)^{a x}$

Where, $\quad \sigma_{\mathrm{h}}=F_{1} \sigma_{\mathrm{h} \mathrm{I}}+F_{2}\left(\sigma_{\mathrm{W}}-\sigma_{\mathrm{WI}}\right)$ is the average horizontal stress in the pillar, $F_{1}$ and $F_{2}$ are factors depending on pillar shape that are evaluated from the finite element analysis, the other two constants $c$ and $a$ were also evaluated from the finite element analysis, $\sigma_{\text {hi } 1}$ is the pre mining horizontal stress, $\sigma_{W}$ is the average vertical pillar stress, $\sigma_{\mathrm{K} I 1}$ is the pre mining vertical stress.

\section{Pillar strength equation by Das}

Das (1986) conducted tests on 6 types of Indian coal adopting a wider range of $w / h$ ratio varying from 0.5 to

13.5. The tests were conducted on cylindrical specimens of NX size (54 mm diameter) with different heights at a constant strain rate of $10^{-3} \mathrm{~s}^{-1}$ in a $1.962 \mathrm{MN}$ (200 tons) closed loop servo-controlled testing machine. It was observed that in general when the $w / h$ ratio increases

beyond 4-6, the post-failure characteristic starts ascending after an initial fall indicating a gain in strength (Figure 2). Das (1986) attributed this phenomenon for the reconsolidation of the broken coal mass. Stating that if the test is not conducted for long enough, the reconsolidation process may not be observed. At the $w / h$

ratio of 13.5 the post-failure slope was throughout positive revealing a remarkable observation which indicates that if the pillars of such flatness are left in underground mines for support purposes they can retain 


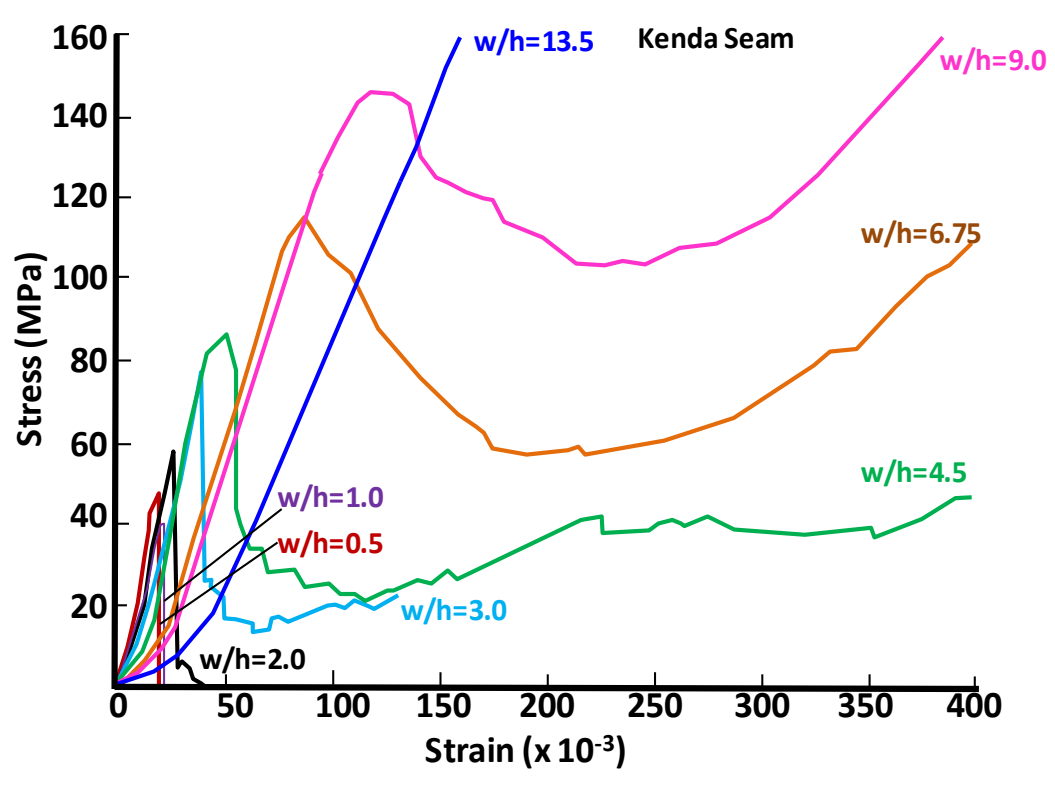

Figure 2. Influence of $w / h$ ratio on the post-failure stress-strain behavior of coal 'calculated from the machine plot - without removing the effect of platen indentation' (modified after Das, 1986).

very high strength even after failure. At $w / h$ ratios less

than 4 to 6 , the residual strength ultimately became zero which can be attributed to lower triaxial confinement at the specimen center. He also analyzed the post-failure modulus (maximum slope after strength failure) against the $w / h$ ratio. The post-failure modulus observed to

become zero around a w/h ratio of 10 and became positive with further increase in $w / h$ ratio.

\section{Pillar strength equation by Mark-Bieniawski}

Mark et al. (1988), and Mark and lannachione (1992) proposed new pillar strength equation which is widely known as the 'Mark-Bieniawski Pillar Strength Equation'. This equation was an improvement over the earlier pillar strength equation described by Bieniawski and Van (1975). Mechanistic approach to pillar design with stress distribution proposed by Wilson (1972a, 1983) could estimate vertical stress gradient within the yield zone, which could then be integrated over the area of the pillar to determine the ultimate pillar resistance. Bieniawski developed Equation 19 by testing square specimens and recognized that the equation underestimated the strength of rectangular pillars (Mark and Chase, 1997). Rectangular pillars and the effect of a pillar's length on its strength were examined and a modified version of equation, the Mark-Bieniawski Equation, was developed. It indicates that the strength of rectangular pillars exhibits a dependence on the width-to-height and width-to-length ratios. The Mark-Bieniawski Equation is as follows (Mark and Chase, 1997):

$C_{p}=S_{1}\left[0.64+\left(0.54 \frac{w_{p}}{h_{p}}-0.18\left(\frac{w_{p}^{2}}{h_{p} L_{p}}\right)\right)\right]$

Where, $S_{1}$ is the in situ coal strength, assumed as 6.2 $\mathrm{MPa}, w_{p}$ is the pillar width, $h_{p}$ is the pillar height, $L_{p}$ is the pillar length. Thus, for Equation 27, as the $w_{p} / h_{p}$ ratio increases so does the strength of the pillar. Additionally, as $w_{p} / L_{p}$ increases the strength also increases. Equation 27 has been used successfully within the ARMPS computer program to design pillars for room and pillar mining.

\section{Madden equation for squat pillars}

Owing to the limitations of Salamon and Munro (1967) equation, which was statistically analyzed for pillars with width to height ratio of 3.6 or less, it proved to be on the conservative side. For pillars at greater depths in excess of $150 \mathrm{~m}$ (this means the pillars must have higher $w / h$ ratio), the equations of Obert - Duvall, and HollandGaddy including Salamon-Munro are too conservative and in fact were never envisioned for this purpose. Only the Mark-Bieniawski equation is still realistic up to a width to height ratio of 10 to 12 . Madden (1991) emphasized this point and reported a modified 'Salamon-Munro Equation' for squat pillars of the following form: 


$$
C_{\mathrm{p}}=k_{M} \frac{R_{0}^{b}}{V^{a}}\left\{\frac{b}{\epsilon}\left[\left(\frac{R_{\mathbb{W E}_{p}}}{R_{0}}\right)^{E}-1\right]+1\right\}
$$

Where $k_{M}$ is the strength of coal sample (normally taken as $7.2 \mathrm{MPa}$ ), $R_{0}$ is the critical width to height ratio taken as $5.0, \varepsilon$ is the rate of strength increase taken as $2.5, a$ and $b$ are constants which are determined statistically $a=0.0667$ and $b=0.5933, R_{w / h}$ is the pillar width to height ratio. All the dimensions are taken in metres.

\section{Pillar strength equation by Sheorey}

Sheorey (1992) gave the equation for pillar strength as:

$$
C_{\mathrm{p}}=0.27 \sigma_{025} h_{\mathrm{p}}^{-0.36}+\left(\frac{H}{250}+1\right)\left(\frac{w_{G}}{h}-1\right) M P a
$$

Where, $C_{\mathrm{p}}$ is the strength of pillar (MPa), $\mathrm{H}$ is the seam depth, $\sigma_{c 25}$ is the strength of coal sample of size $25 \mathrm{~mm}$ cube, $W_{e}$ is the solid pillar width $(\mathrm{m})$, and $h_{p}$ is the pillar height or working height $(\mathrm{m})$. Equation 29 can be used for strength calculation of stooks as well. Since ribs are designed to fail eventually, Equation 29 was modified by Sheorey as follows:

$C_{p}=0.27 \sigma_{\sigma 25} \frac{\sqrt{w_{g}}}{h_{\mathrm{p}}} \mathrm{MPQg} \mathrm{Pa}$

Equation 30 was found to be a very good fit to the 14 failed cases and therefore is widely accepted for calculation of rib strength. The ribs are generally of low $\mathrm{w} / \mathrm{h}$ ratio and one width is much greater than the other. Equation 30 can therefore be changed for long ribs to:

$S=0.4 \sigma_{c} \frac{\sqrt{W}}{h^{0.8 s}} M P a$

It may be noted that Equation 31 should be used only for the strength calculation of long ribs whose shorter width (w) is such that ${ }^{W} / h \leq 3,0$.

\section{Maleki equation for squat pillars}

There exists a general belief that for squat pillars, the strength goes on increasing as the $\mathrm{w} / \mathrm{h}$ ratio increases. The pillar becomes indestructible at a very high $w / h$ ratio. However, Maleki (1992) reported failure of 7 US coal seams. His work based on numerical analysis, stress measurement and in situ closure grouped the 7 US coal seams into two and the best fit regression was given as:

$C_{\mathrm{p}}=4700\left[1-e^{-0.339 \frac{\mathrm{w}_{\mathrm{p}}}{h_{\mathrm{p}}}}\right] \mathrm{psi}$,
$C_{p}=3836\left[1-e^{-0.260 \frac{W_{p}}{h_{p}}}\right]$ psi,

Equation 32 was developed for strong seams analyzed on confinement control method. For seams where failure can be analyzed as structural control, the Equation 33 was derived accordingly.

\section{Observation by Mark and Barton on pillar strength}

Mark et al. (1997) summarized the work of a group of researchers who have determined that the value of in situ coal strength falls between 5.4 to $7.4 \mathrm{MPa}$. Mark et al. (1997) performed a statistical analysis that found no correlation between the stability of failed pillars and strength of coal specimen which indicated that pillar design was much more reliable when uniform coal strength was used. They identified many sources of unreliability in coal strengths viz. material variability within a particular seam, variation in sampling, specimen preparation, testing techniques and variation in size and shape effects between seams.

\section{Observation by Gale on pillar strength}

Gale (1999) viewed pillar as a system in which failure occurred in the strata rather than coal only; he came out with a wide range of pillar strength characteristics. The variations in these pillar strength characteristics were due to different strata - coal combinations not different coal strengths (Figure 3 ).

He concluded that the degree of confinement provided to the coal seam is a major factor in determining the pillar strength. If the roof and/or floor are themselves yielding and deforming (weak strata), under such circumstances the confinement the roof/floor which it can give to the coal rib side will drop.

\section{Numerical method for pillar strength determination}

Murali et al. (2001) used the strain softening option in FLAC3D to evaluate the pillar strength of 14- failed cases and 15- unfailed cases of Indian coal seams. The equivalent Mohr coulomb fit for Sheorey's failure criteria was used in the stain softening model. This modeling had a satisfactory agreement with the Sheorey's (1992) equation.

Sheorey (2006) reported numerical modeling studies for deep seated squat pillars of two mines, viz. Chinakuri No. I Mine and Jitpur Colliery using the strain softening model in FLAC3D. The results of numerical modeling were in good agreement with the Maleki (1992) squat pillar equation. The equations of Logie and Matheson. (1982), Madden (1991) and Sheorey (1992) predicted very high values in comparison with the modeled results. 


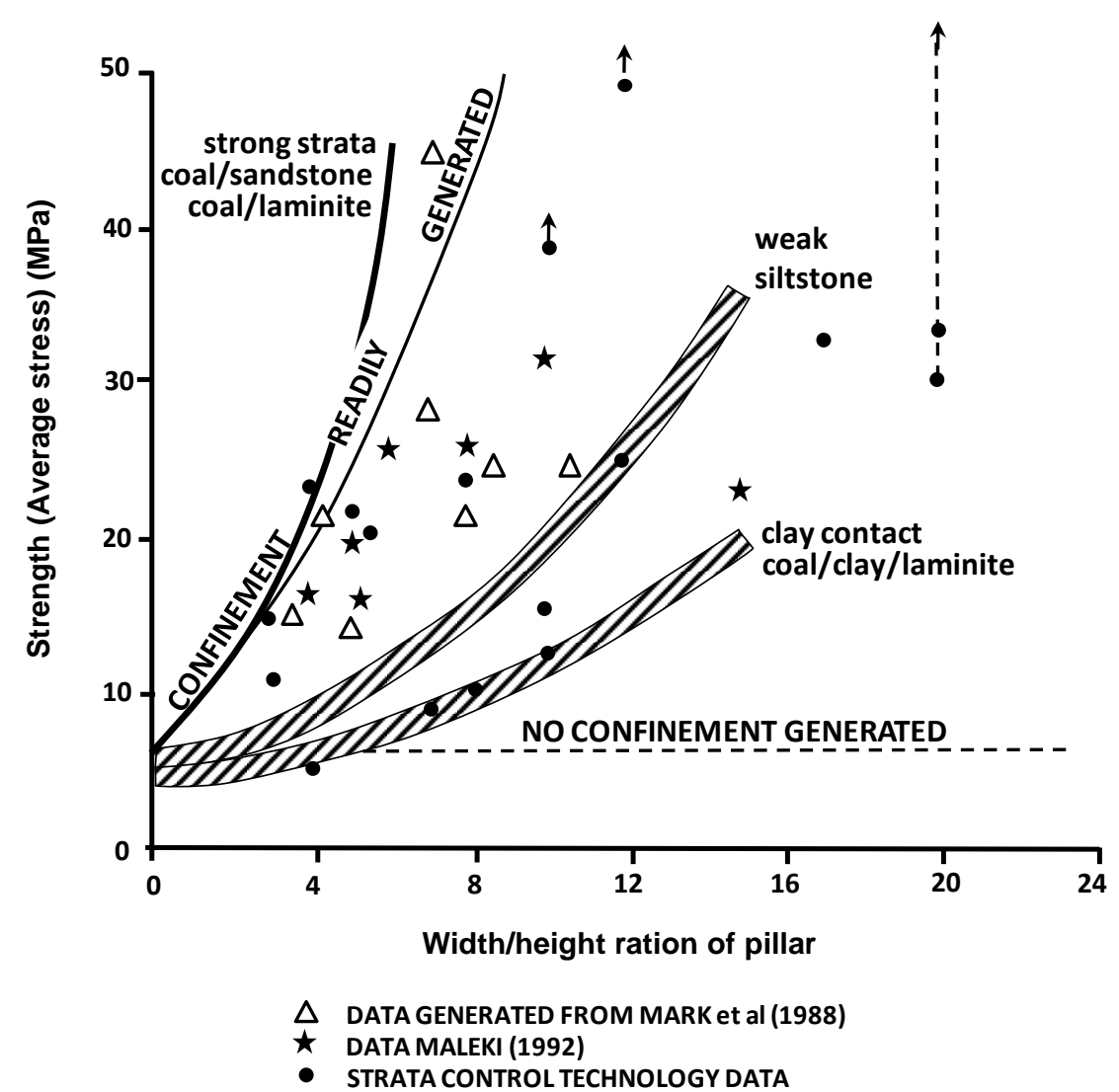

Figure 3. Strength and $w / h$ for different geologic conditions (After Gale, 1999).

However, the post failure characteristics of the modeled pillar agreed well with the results for squat coal specimens.

\section{Comparison of the pillar strength equations}

Any pillar strength equation can be best judged by its suitability to fit the actual cases of pillar (stable or unstable). Sheorey (2006) elaborated the performance of some equations for failed and stable cases from Indian coalfields. The guiding philosophy for assessment of any pillar equation is, firstly the line of factor of safety $=1.0$ must be the best fit for all collapse cases. Secondly, all stable cases must have a factor of safety higher than 1.0. Scrutiny of the pillar equations based on this principle, suggests that for Indian conditions, the Sheorey (1992) equation is the best predictor.

A graph of pillar strength prediction for different equations is shown in Figure 4. In order to compare these equations on a common platform, the height of pillar is kept constant to $3.0 \mathrm{~m}$ and the width is varied to observe the influence of width to height ratio on strength of the pillar. The strength of the coal is common wherever the equations demand it. The strength of laboratory size specimen of $25 \mathrm{~mm}$ size is taken as $26 \mathrm{MPa}$ and in situ strength of $30 \mathrm{~cm}$ specimen is taken as $7.6 \mathrm{MPa}$, a realistic value as reported by Sheorey (2006) for analysis of Begonia seam. The graph is interpreted in two parts, first the slender part (width to height ratio up to 6.0) and second, the squat part (Sheorey, Mark-Bieniawski, Madden Modified Bieniawski and Wilson, 1983; Case Ila equations). The baseline for best predictor is the Sheorey (1992) equation.

In case of slender pillars, it is observed that the Generalized Salamon-Munro equation (1967) is in close agreement with the Sheorey (1992) equation. The Grenwald equation (1941), Gaddy equation (1946) and Wilson equation Case Ila (1983) underestimates the pillar strength. Rest of the other equations viz. Cook et al. (1971), Obert and Duvall (1967), Mark-Bieniawski, Zern (1928) and Bieniawski (1975) overestimates the pillar strength.

In case of squat pillars, considering again the baseline as Sheorey (1992) equation, it is observed that the Zern (1928) equation initially over predicts the strength up to a $\mathrm{w} / \mathrm{h}$ ratio of 14.0 and then under predicts the strength of the pillars beyond $a \mathrm{w} / \mathrm{h}$ ratio of 14.0. A similar observation is made with respect to the Maleki (1992) equation for strong coal with a cutoff at a w/h ratio of 18.0 


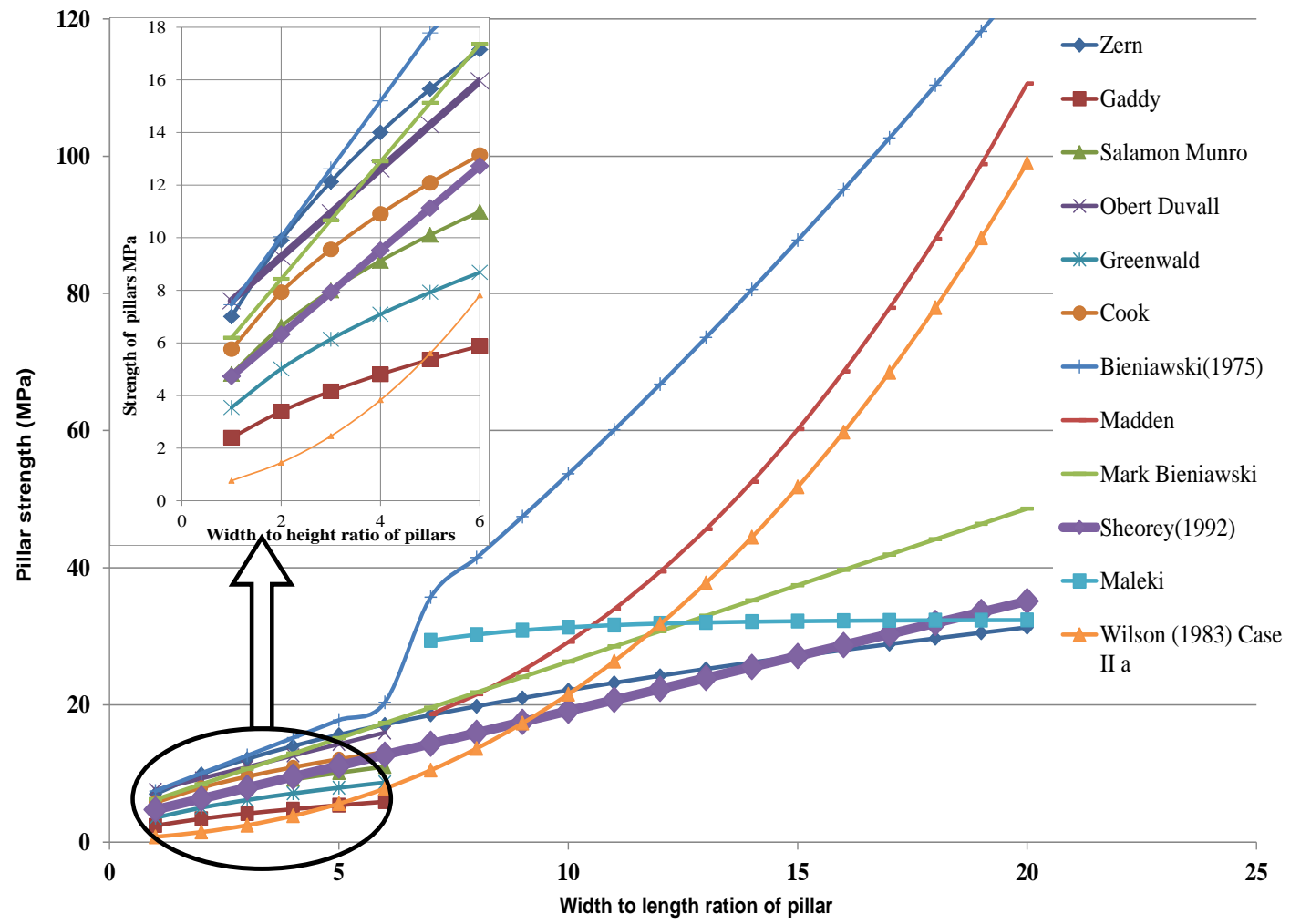

Figure 4. Comparison of different pillar strength equations.

and the Wilson (1983) equation Case Ila at a cut-off ratio of 9.0. Rest of the other equations of Mark-Bieniawski, Madden (1991) and Bieniawski and Van (1975) modified by Logie and Matheson (1982) over predicts the strength of squat pillars to a considerable value.

\section{Conclusion}

Different approaches for pillar design have been discussed in this paper. The suitability of the pillar design approaches, however, remain quite difficult as mentioned by Mark and Barton (1997) "despite the fact that textbooks have considered laboratory testing as an integral part of pillar design for nearly 30 years, it has remained controversial. One reason is that coal remains notoriously difficult to test." The empirical methods are the best design approach towards the pillar design in particular conditions, provided they meet the performance criteria with respect to failed and stable cases of pillars. Any pillar design by numerical or other methods must be compared with the empirical relations of other workers as well as the locally developed empirical relations.

The Maleki (1992) observation of failed squat pillars throws light on the requirement of further research in the field of squat pillars. Numerical analysis of pillars based on elasto - plastic models is quite debatable especially with respect to the proper use of the input data and the mesh size; this throws light on another grey area for pillar research through numerical methods.

\section{REFERENCES}

Bieniawski ZT (1968). The effect of specimen size on compressive strength of coal. Int. J. Rock Mech. Min. Sci. Geomech. Abstr. 5(4):325-326, IN5-IN10, 327-335. DOI: 10.1016/01489062(68)90004-1.

Bieniawski ZT, Van HWL (1975). The significance of in situ tests on large rock specimens. Int. J. Rock Mech. Min. Sci. Geomech. Abstr. 12(4):101-113.

Bieniawski ZT (1976). Rock mass classification in rock engineering. In Exploration Rock Eng. Proc. Symp. (ed. Z.T. Bieniawski) 1. Cape Town, Balkema. pp. 97-106.

Bunting D (1911). Chamber-Pillars in Deep Anthracite-Mines, (KrilkesBarre Meeting), Trans. AIME 42:236-245.

Cook NGW, Hodgson K, Hojem JPM (1971). A 100 MN jacking system for testing coal pillars underground. J. South Afr. Inst. Min. Metallurgy. pp. 215-224.

Das MN (1986). Influence of width/height ratio on post-failure behaviour of coal. SHORT COMMUNICATION. Int. J. Min. Geol. Eng. 4:79-87.

Gaddy FL (1956). A study of the ultimate strength of coal as related to the absolute size of cubical specimens tested. Virginia Polytech. Bull. pp. 1-27.

Gale WJ (1999). Experience of field measurement and computer simulation methods for pillar design, Proc Second International Workshop on Coal Pillar Mechanics and Design, PA: U.S. Department of Health and Human Services, Centers for Disease Control and Prevention, National Institute for Occupational Safety and Health, DHHS (NIOSH) Publication No. 99 - 114, IC 9448 pp. 49-61.

Greenwald HP, Howarth HC, Hartman I (1941). Experiments on the 
strength of small pillars in the Pittsburgh bed. U.S. Bur. Mines, R.I P. 3575.

Holland CT, Gaddy FL (1956). Some aspects of permanent support of overburden on coal beds. Proceed. Virginia Coal Min. Inst. pp. 43-65.

Holland CT, Gaddy FL (1964). The strength of coal in mine pillars, Proc 6th US Symp. on Rock Mechanics (University of Missouri, Rolla, MO) pp. 450-466.

Hustrulid WA (1976). A review of coal pillar strength formulas. Rock Mech. Rock Eng. 8(2):115-145, DOI: 10.1007/BF01239762.

Logie CV, Matheson GM (1982). A critical review of the current state of the art design of mine pillars. 1st Int. Conf. Stability in Underground Min. Vancouver (Ed. C.O. Brawner) pp. 359-382.

Madden BJ (1991). A re-assessment of coal - pillar design. J. South Afr. Inst. Min. Metallurgy 91(1):27-37.

Maleki H (1992). In-situ pillar strength and failure mechanism for U.S. coal seams. Workshop on coal pillar mechanics and design. Santa Fe. U.S. Bur. Min. IC 9315.

Mark C (2006). The Evolution of Intelligent Coal Pillar Design: 19812006. Proceedings, 25th International Conference on Ground Control in Mining, Morgantown, West Virginia. pp. 325-334.

Mark C, Barton TM (1997). Pillar design and coal strength, Proceedings: New technology for ground control in retreat mining, IC 9446, NIOSH, pp. 49-59.

Mark C, Chase FE (1997). Analysis of retreat mining pillar stability, Proceedings: New technology for ground control in retreat mining, IC 9446, NIOSH. pp. 1-34.

Mark C, lannachione A (1992). Coal Pillar Mechanics: Theoretical Models and Field Measurements Compared. Proc. Workshop on Coal Pillar Mechanics and Design. US Dept. Interior. I.C. 9315, pp. 78-93.

Mark C, Listak JM, Bieniawski ZT (1988). Yielding coal pillars - field measurements and analysis of design methods. Proceedings of the 29th U.S. Symposium on Rock Mechanics. Minneapolis, MN: University of Minnesota, pp. 261-270.

Murali MG, Sheorey PR, Kushwaha A (2001). Numerical estimation of pillar strength in coal mines. Int. J. Rock. Mech. Min. Sci. 38:11851192.

Obert L, Duvall WI (1967). Rock Mechanics and the Design of Structures in Rock, John Wiley \& Sons Inc. New York pp. 542-545.

Pariseau WG (1982). Shear stability of mine pillars in dipping seams. In Issues in rock mechanics. Proc. 23rd U.S. Sym. Rock Mech. pp. 107190.

Pariseau W (1982). Shear stability of mine pillars in dipping seams. In The 23rd US Symposium on Rock Mechanics (USRMS).
Salamon MDG, Munro AH (1967). A study of the strength of coal pillars. J. South Afr. Inst. Min. Metallurgy 68:55-67.

Sheorey PR (1992). Pillar strength considering in situ stress, Proceedings of the Workshop on Coal Pillar Mechanics and Design, Santa Fe, Ed. A.T. Iannacchione et al., 122 - 127. USBM IC 9315.

Sheorey PR (2006). Ground control in bord and pillar mining. A golden jubilee monograph published by CMRI, Dhanbad, India.

Sheorey PR, Bandopadhyay C, Das MN, Singh TN, Biswas AK, Prasad RK, Barat D, Ramna R (1987). Optimisation of design of mine pillar parameters and feasibility of extraction of locked up coal below builtup structures, water logged areas and hard cover. CMRS Report on partially funded coal S\&T grant of Department of Coal, Ministry of Energy Government of India.

Sheorey PR, Das MN, Brodia SK, Singh B (1986). Pillar strength approaches based on a new failure criterion for coal seams. Int. J. Min. Geol. Eng. 4:273-290.

Trumbachev VF, Melnikov EA (1964). Distribution of stresses in the intervening pillars at medium and steep dips. 4th Conference on strata control and rock mechanics, New York. pp. 316-322.

Wagner H (1974). Determination of the Complete Load-Deformation Characteristics of Coal Pillars. Proc.3rd. ISRM Congr. pp.1076-1081.

Wagner H (1980). Pillar Design in Coal Mines. J. South Afr. Inst. Min. Metallurgy pp. 37-45.

Wilson AH (1972a). Research into the determination of pillar size. Min. Eng. 131:409-416.

Wilson AH (1972b). A hypothesis concerning pillar stability. Mining engineering (London) 131(141):409-417.

Wilson $\mathrm{AH}$ (1983). The stability of underground workings in the soft rocks of the Coal Measures. Geotech. Geol. Eng. 1(2):91-187, DOI: 10.1007/BF00880785.

Zern EN (1928). Coal miners' pocketbook: principles, rules, formulas and tables, McGraw-Hill Book Co., Inc. Science 1273 P. 